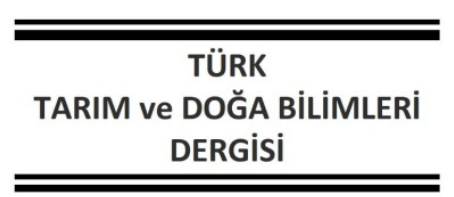

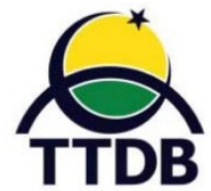

www.dergipark.gov.tr/turkjans

Araştırma Makalesi

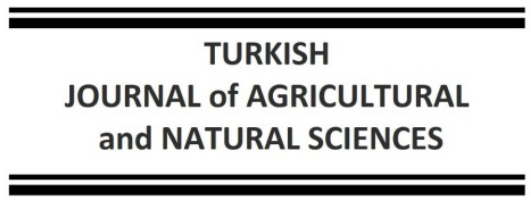

OURNAL Of AGRICULTURAL

\title{
Bitkisel Malç Miktarının Ekmeklik Buğdayda Biyomas, Tane Verimi ve Hasat İndeksi Üzerindeki Lineer ve Kuadratik Etkileri\&
}

\author{
Muhammed Alim YILMAZ ${ }^{1 *}$, Cengiz YÜRÜRDURMAZ ${ }^{1}$, Rukiye KARA ${ }^{2}$, Duygu KAZANCI ${ }^{1}$, Songül YILMAZ ${ }^{1}$, \\ Yasemin KEÇECIOĞLU², Aydın AKKAYA ${ }^{1}$
}

${ }^{1}$ Kahramanmaraş Sütçü İmam Üniversitesi Ziraat Fakültesi Tarla Bitkileri Bölümü

${ }^{2}$ Doğu Akdeniz Geçit Kuşağı Tarımsal Araştırma Enstitüsü

*Sorumlu Yazar: muhammedalimyilmaz@gmail.com

Geliş Tarihi: 13.10.2020 Düzeltme Geliş Tarihi: 22.03.2021 Kabul Tarihi: 07.04.2021

\section{$\overline{0 ̈ z}$}

Buğday tarımında bitkisel malç uygulaması toprak organik maddesi ve kalitesinin, su kullanım etkinliğinin, verim ve verim unsurlarının artırılması yönünden önemli yararlar sağlamaktadır. İklim ve toprak özellikleri, malç tipi, miktarı, uygulama şekli ve zamanı gibi faktörlere bağlı olarak malç materyallerinin etkinliği önemli derecede değişebilmektedir. Malç uygulamalarının Adana 99 ekmeklik buğday çeşidi üzerindeki etkilerini belirlemek amacıyla Kahramanmaraş koşullarında 2018-2019 yılında bir çalışma yürütülmüştür. Malç olarak buğday samanı kullanılmış, 4 farklı miktarda $\left(0,300,600\right.$ ve $900 \mathrm{~kg} \mathrm{da}^{-1}$ ) ve 3 farklı zamanda (ekimden hemen sonra, sapa kalkma başlangıcında, gebecik döneminde) uygulama yapılmıştır. Deneme, faktöriyel düzenleme yapılarak, tesadüf blokları deneme planına göre, 3 tekerrürlü olarak yürütülmüştür. Bu makalede, kantitatif faktör olan malç miktarı esas alınarak biyomas, tane verimi ve hasat indeksi üzerindeki lineer ve kuadratik etkiler incelenmiştir. Çalışmada, malç miktarının biyomas üzerindeki lineer etkisinin önemsiz, kuadratik etkisinin önemli, tane verimi ve hasat indeksi üzerindeki lineer ve kuadratik etkilerin her ikisinin de önemli olduğu ve $300 \mathrm{~kg} \mathrm{da}^{-1}$ malç miktarının yeterli olabileceği sonucuna varılmıştır.

Anahtar kelimeler: Buğday, bitkisel malç, biyomas, tane verimi, hasat indeksi, lineer ve kuadratik etkiler

\section{The Linear and Quadratic Effects of the Amount of Straw Mulching on Biomass, Grain Yield and Harvest Index of Bread Wheat}

\begin{abstract}
The straw mulching in wheat production provides important benefits in terms of improving the soil organic matter and quality, the water use efficiency, yield and yield components. The efficiency of the mulching materials could be significantly changed by the factors such as soil and climate conditions, the type, amount, application method and time of the mulching materials. The field experiment was carried out to determine the effects of straw mulching on bread wheat cultivar Adana 99 during 2018-2019 crop season in Kahramanmaraş conditions. The wheat straw as mulch material was used and applied in 4 different rates $\left(0,3,6\right.$ and 9 t ha $\left.^{-1}\right)$ and at 3 different stages (soon after planting, at the beginning of stem elongation and booting stage). The research was carried out as factorial arrangement on the randomized complete block design with 3 replications. In this article, mulch amount as quantative factor was based and the effects of linear and quadratic on biomass, grain yield and harvest index were investigated. It was concluded that the quadratic effect on biomass was significant, while linear effect nonsignificant, both the linear and quadratic effects on grain yield and harvest index were significant and the amount of $3 \mathrm{t} \mathrm{ha}^{-1}$ straw mulch could be applicable.
\end{abstract}

Key words: Wheat, straw mulching, biomass, grain yield, harvest index, linear and quadratic effects. 


\section{Giriş}

Bitkisel malç toprak muhafaza, toprak ekolojisi ve bitki verimi üzerinde önemli etkilere sahiptir (Erenstein, 2002). Toprak ıslahı ve nem etkinliği yönünden bitki artıklarının toprağa geri kazandırılması büyük önem taşımakta olup, bu yöndeki uygulamalar giderek yaygınlaşmaktadır (Anderson, 2005). Bitki artıklarının toprağa geri kazandırıması, toprağın organik madde miktarını artırmış ve agregat yapısını iyileştirmiş (Malhi ve Kutcher, 2007), çevre koruma ve sürdürülebilir verim açısından yararlı olmuştur (Malhi ve Lemke, 2007). Bitkisel malç uygulanan ve işlenmeyen topraklarda, ilk $10 \mathrm{~cm}$ derinlikteki makro agregatlar (>250 milimikron) fazla su tutmuş ve yüksek hidrolik iletkenliğe sahip olmuştur (Zhang ve ark., 2008). Buğday saplarının toprağa geri verilmesiyle özellikle ilk $5 \mathrm{~cm}$ derinlikte toprak özellikleri değişmiş, balk yoğunluğu \%40-50, agregat yoğunluğu \%30-40, partikül yoğunluğu \%10-15, tutulan su miktarı \%30, agregat direnci 14 kat artırmıştır (Blanco-Canqui ve Lal, 2007). Toprağa 0, 800 ve 1600 kg da-1 bitkisel malç uygulamalarını içeren 22 yıllık bir araştırma sonucuna göre, toprak kalitesinin arttığı, toprağın fiziksel ve hidrolik özelliklerinin iyileştiği belirlenmiştir (Kahlon ve ark., 2013).

Anızın korunması toprak kalitesi, toprak organik maddesi ve nem tutulmasını artırmış, besin döngüsünü iyileştirmiş, toprak kaybını önleyerek çevre ve toprak sağlığı yönünden yararlı olmuştur (Turmel ve ark., 2015). Dekara 675 kg samanın malç olarak kışlık buğdaya uygulanması su kullanım etkinliğini \%17, verimi \%16 kadar artırmış (Huang ve ark., 2012), dekara 150-500 kg malç uygulanması halinde bile verim, fizyolojik özellikler ve toprak özelliklerinde önemli düzeyde iyileşmeler olmuştur (Stagnari ve ark., 2014). Yağış ve kuraklığın yıllara göre değişen etkilerine bağlı olarak, buğdayın su kullanım etkinliği ve tane verimi de önemli oranda değişmektedir. Ancak malç uygulamasıyla, verim ve su kullanım etkinliğindeki yıllara bağlı değişkenlik önlenebilmiş, geleneksel sisteme göre tane verimi $\% 35$, su kullanım etkinliği \%25 artmıştır (Chen ve ark., 2015).

Bitki artıklarının malç olarak kullanılması halinde evaporasyon ve yüzey akışın azaldığı, yabancı otların baskı altına alındığı, toprak organik maddesi ve yapısını iyileştirmesi suretiyle topraktan nem kaybının azaldığı bildirilmiştir (Singh ve ark., 2005). Çeltik bitki artıklarının malç olarak kullanılması halinde buğday verimi ve toprak nemi artmış (Rahman ve ark., 2005; Sidhu ve ark., 2007), buğdayın sulama suyu ihtiyacı $75 \mathrm{~mm}$ kadar azalmıştır (Sing ve ark., 2011).

Bitkisel malçın olumlu etkileri toprak işleme, iklim ve toprak özellikleri yanında, malç miktarı ve kalitesi tarafından da etkilenebilmektedir (Blanco-
Canqui ve Lal, 2007). Örneğin, bir araştırma sonucuna göre 700 kg da-1'lik malç önerilirken (Baumhardt ve Lascano, 1996), başka bir araştırmada su infiltrasyonunu artırmak için $150 \mathrm{~kg}$ da-1'lik buğday sap malçının gerektiği ifade edilmiştir (Lentz ve Bjorneberg, 2003). Mısır bitkisinde $400 \mathrm{~kg}$ da-1 bitkisel malç miktarında olumlu bir etki görülmezken, miktarın 670 kg da-1 çıkarılması halinde tane veriminde \%17, biyomasta \%19 düzeyinde artış meydana gelmiştir (Tolk ve ark., 1999).

Malçın eğimli arazilerde fazla etkili olmadığı, düz arazilerde ise $20-28 \mathrm{~mm}$ daha fazla toprak nemi sağladığı belirtilmiştir (Zhang ve ark., 2009). Yetersiz nem koşullarında, organik malç olarak çeltik kavuzlarının kullanılması halinde biyomas, tane verimi ve su kullanım etkinliği artmıştır (Chakraborty ve ark., 2008; Ram ve ark., 2013). Dekara 200 ve $400 \mathrm{~kg}$ bitkisel malç uygulaması, yüzey akışını sırasıyla \%21 ve 51 oranlarında azaltmış, malç miktarının artırılması toprakta tutulan nem miktarını önemli düzeyde artırmıştır (Montenegro ve ark., 2013). Bitkisel malç uygulaması su kullanım etkinliği yanında, besin elementi kullanım etkinliği yönünden de yararlı olmaktadır. Buğday bitkisinin azot alım ve kullanım etkinliği, artan buğday anızı miktarına bağlı olarak önemli derecede artmış, \%75 anız artığı bulunması, kontrole göre azot alım etkinliğini \%61 kadar artırmıştır (Ebrahimian ve ark., 2016).

Organik malçın sentetik malçtan daha yararlı olduğu, malçsız sisteme göre organik malçın buğdayda kök ağırığını \%25, kök uzunluğunu \%40 kadar artırdığı, bu artışların muhtemelen toprakta tutulan nemin artmasından kaynaklandığı, tane veriminin \%13-21, su kullanım etkinliğinin \%25 kadar arttığı belirtilmiştir (Chakraborty ve ark., 2010). Kuru topraklara kıyasla, yeterli miktarda nem içeren topraklarda bitkisel malçın evaporasyonu azaltmak yönünden daha etkili olduğu, organik ve inorganik nitelikteki diğer malçlara kıyasla buğday saplarının daha yararlı olduğu belirlenmiştir (Zribi ve ark., 2015).

Konu ülkemizde oldukça erken dönemde ele alınmış, kıraç koşullarda dekara 1000 kg sap-saman uygulamasının buğdayda \%40 verim artışı sağladığı belirtilmiştir (Gerek, 1968). Ancak, bu yöndeki çalışmalar sonraki yıllarda gerekli düzeyde ele alınmamış, kuru tarımda geleneksel üretim sistemlerine devam edilmiş ve halen devam edilmektedir. Oysa, her yöreye özgü ekolojik, sosyoekonomik ve tarımsal koşullar altında araştırmaların yapılması ve bitkisel malç uygulama potansiyelinin belirlenmesini önerilmektedir (Erenstein, 2002). Bu nedenle, Kahramanmaraş koşullarında 2018-2019 ürün sezonunda malç miktar ve uygulama zamanını esas alan bir çalışma 
yürütülmüştür. Deneme faktörlerinden kantitatif nitelikte olan malç miktarı esas alınarak biyomas, tane verimi ve hasat indeksi üzerindeki lineer ve kuadratik etkiler bu makaleye konu edilmiştir.

\section{Materyal ve Metot}

Kahramanmaraş koşullarında 2018-2019 ürün yılında yürütülmüş olan bu araştırmada, yörede en fazla ekimi yapılan çeşitlerden biri olan Adana-99 ekmeklik buğday çeşidi kullanılmıştır. Bitkisel malç olarak buğday samanı kullanılmış, 4 farklı miktar (0, 300, 600 ve $900 \mathrm{~kg} \mathrm{da-1)}$ ve 3 farklı zamanda (ekimden hemen sonra, sapa kalkma başlangıcında, gebecik döneminde) parsellere homojen bir şekilde elle dağıtılmıştır. Deneme, faktöriyel düzenleme yapılarak tesadüf blokları deneme planına göre 3 tekerrürlü olarak yürütülmüştür. Ekim sıklığı 500 tane $\mathrm{m}^{2}$, parsel uzunluğu $8.3 \mathrm{~m}$, parsel genişliği $1.2 \mathrm{~m}$ olarak düzenlenmiş ve parsel makinesiyle ekilmiştir. Ekimle birlikte $6 \mathrm{~kg} \mathrm{da}^{-1} \mathrm{~N}$ ve $\mathrm{P}$, sapa kalkma başlangıcında $8 \mathrm{~kg} \mathrm{da}^{-1} \mathrm{~N}$ uygulanmıştır (Akkaya, 1994). Bitkiler tam olgunluk dönemine geldiklerinde parsel başlarından $50 \mathrm{~cm}$, parsel kenarlarından 1 sıra kenar tesiri olarak atılmış, kalan kısım toprak seviyesinden orakla hasat edilmiştir. Bitkiler birkaç gün süreyle kurutulduktan sonra tartılmış ve biyomas verimleri $\mathrm{kg} \mathrm{da}^{-1}$ olarak ifade edilmiştir. Bitkiler parsel hasat makinesiyle harman edildikten sonra, elde edilen tane ürünü temizlenip tartılmış ve değerler $\mathrm{kg} \mathrm{da}^{-{ }^{-1}} \mathrm{a}$ çevrilerek tane verimi belirlenmiştir. Her parsele ait tane verimi biyomasa oranlanıp 100 ile çarpılarak hasat indeksi \% olarak hesaplanmıştır. Sonuçlara ait istatistiksel hesaplamalarda SAS paket programı kullanılmıştır (SAS, 1999).

\section{Bulgular ve Tartışma Biyomas}

Malç miktarlarına göre biyomas verimleri, malç miktarı, lineer ve quadratik etkilere ilişkin $\mathrm{F}$ değerleri Çizelge $1^{\prime}$ de verilmiştir. ilgili çizelgenin incelenmesinden görüleceği gibi malç miktarının biyomas verimi üzerindeki etkisi önemli olmuştur $(P<0.05)$.

Çizelge 1. Malç miktarlarına göre ortalama biyomas verimleri, lineer ve kuadratik etkilere ilişkin $\mathrm{F}$ değerleri.

\begin{tabular}{cccc}
\hline Malç miktarı $\left(\mathrm{kg} \mathrm{da}^{-1}\right)$ & Biyomas $\left(\mathrm{kg} \mathrm{da}^{-1}\right)$ & \multicolumn{2}{c}{ Varyans analiz sonuçları } \\
\hline 0 & $1698 \mathrm{~b}$ & Varyasyon kaynağı & F değeri \\
\hline 300 & $1908 \mathrm{a}$ & Malç miktarı & $3.30^{*}$ \\
\hline 600 & $1824 \mathrm{ab}$ & Lineer etki & 1.11 \\
\hline 900 & $1801 \mathrm{ab}$ & Kuadratik etki & $5.99^{*}$
\end{tabular}

*işaretli F değerleri \% 5 düzeyinde önemlidir.

\section{Biyomas}

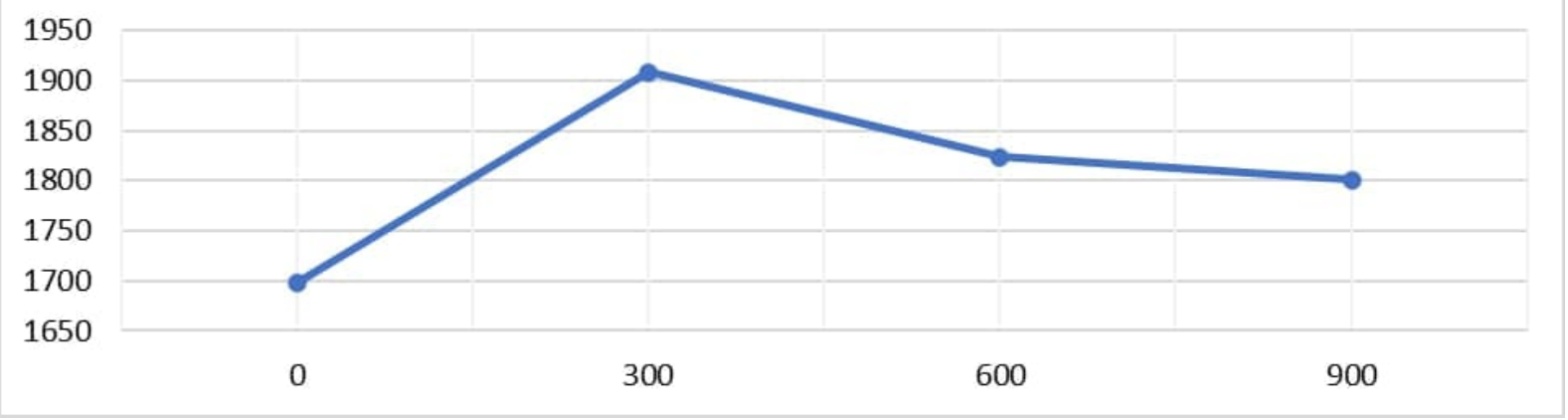

Şekil 1. Malç miktarlarına göre biyomas verimleri.

Dekara 0, 300, 600 ve 900 bitkisel malç uygulamalarındaki biyomas değerleri sırasıyla 1698, 1908, 1824 ve $1801 \mathrm{~kg} \mathrm{da}^{-1}$ olmuştur. En yüksek biyomas verimi $300 \mathrm{~kg} \mathrm{da}^{-1}$ malç uygulamasından alınmış, 600 ve $900 \mathrm{~kg} \mathrm{da}^{-1}$ 'lik malç uygulamalarıyla arasındaki fark önemsiz olmuştur. Çizelge 1'deki varyans analiz sonuçlarından görüleceği gibi, malç miktarının biyomas üzerindeki lineer etkisi önemsiz olurken, kuadratik etkisi ise önemli $(P<0.05)$ bulunmuştur. Dekara $300 \mathrm{~kg}$ malç uygulaması biyomas veriminde kontrole göre önemli bir artış sağlamış, ancak malç miktarının daha fazla artması biyomas veriminde önemsiz de olsa giderek bir azalmaya yol açmıştır (Şekil 1). Malç miktarıyla biyomas verimi arasında, doğrusal etki yerine kudratik etki öne çıkmış, $300 \mathrm{~kg} \mathrm{da}^{-1}$ malç miktarı dönüm noktasını oluşturmuştur.

Tolk ve ark. (1999) tarafından mısır bitkisinde yapılan bir çalışmada, $400 \mathrm{~kg} \mathrm{da}^{-1}$ bitkisel malç uygulamasında olumlu bir etki görülmezken, miktar $670 \mathrm{~kg} \mathrm{da}^{-1}$ çıktığında biyomasın \%19 arttığı tespit edilmiştir. Diğer çalışmalarda da yetersiz nem 
koşullarında organik malç olarak çeltik kavuzlarının kullanılması halinde biyomasın arttığı rapor edilmiştir (Chakraborty ve ark., 2008; Ram ve ark., 2013). Kahramanmaraş koşullarında 2017-2018 ürün yılında yapılan bir çalışmada ise, malç miktarının biyomas üzerindeki etkisi yönünden kararlı bir sonuç alınamamıştır (Yılmaz, 2019).

\section{Tane verimi}

Uygulanan malç miktarlarına göre elde edilen tane verimleri, malç miktarı, lineer ve kuadratik etkilere ilişkin $F$ değerleri Çizelge 2'de verilmiştir. İlgili çizelgenin incelenmesinden görüleceği gibi, malç miktarının tane verimi üzerindeki etkisi önemli olmuştur $(P<0.01)$. Dekara
$0,300,600$ ve $900 \mathrm{~kg}$ bitkisel malç uygulamaları sırasıyla 509, 636, 621 ve $628 \mathrm{~kg}$ da-1 tane verimi sağlamış, kontrol uygulamasından elde edilen tane verimi önemli derecede düşük kalmış, ancak 300, 600 ve $900 \mathrm{~kg} \mathrm{da}^{-1}$ malç uygulamaları arasındaki fark önemli olmamıştır. Malç miktarının tane verimi üzerindeki etkisi lineer ve kuadratik etkilerine parçalandığında her iki etki şekli de önemli bulunmuştur $(P<0.01)$. Dekara $300 \mathrm{~kg}$ malç uygulamasının kontrol uygulamasına göre sağladığı etki lineer etkinin önemli çıkmasına yol açmış, ancak tane verimi bu noktadan itibaren kararlı bir duruma geçmiş, malç miktarının daha fazla artması halinde tane veriminde önemli bir artış olmamış (Şekil 2) ve kuadratik etki önemli bulunmuştur.

Çizelge 2. Malç miktarlarına göre ortalama tane verimleri, lineer ve kuadratik etkilere ilişkin $\mathrm{F}$ değerleri.

\begin{tabular}{cccc}
\hline Malç miktarı $\left(\mathrm{kg} \mathrm{da}^{-1}\right)$ & Tane verimi $\left(\mathrm{kg} \mathrm{da}^{-1}\right)$ & \multicolumn{2}{c}{ Varyans analiz sonuçları } \\
\hline 0 & $509 \mathrm{~b}$ & Varyasyon kaynağı & F değeri \\
\hline 300 & $636 \mathrm{a}$ & Malç miktarı & $16.43^{* *}$ \\
\hline 600 & $621 \mathrm{a}$ & Lineer etki & $26.73^{* *}$ \\
\hline 900 & $628 \mathrm{a}$ & Kuadratik etki & $16.36^{* *}$ \\
\hline
\end{tabular}

**işaretli F değerleri \% 1 düzeyinde önemlidir.

Tane verimi

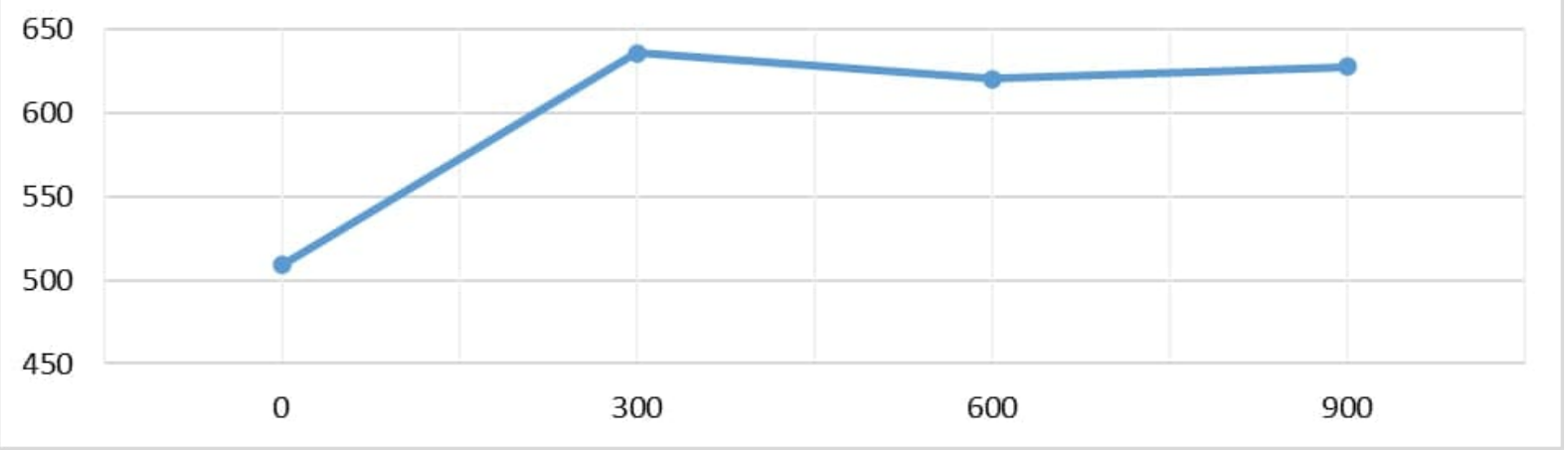

Şekil 2. Malç miktarlarına göre tane verimleri.

Ülkemizde, kıraç koşullarda dekara 1000 kg sap-saman uygulamasının buğdayda \% 40 verim artışı sağladığı belirtilmiş (Gerek, 1968), ancak Kahramanmaraş koşullarında 2017-2018 ürün yılında yapılan çalışmada malç uygulamasının tane verimi üzerindeki etkisi yönünden kararlı bir sonuç elde edilememiştir (Yılmaz, 2019). Diğer çok sayıda çalışmada, malç uygulanması halinde buğdayda tane veriminin arttığı bildirilmiş olup (Huang ve ark., 2005; Chakraborty ve ark., 2008; Ram ve ark., 2013; Shah ve ark., 2013; Chen ve ark., 2019), bu araştırmadan elde edilen sonucu desteklemektedir. Yine Qi ve ark., (2019), bitkisel artıkların toprağa kazandırılmasının buğday veriminde ortalama \%8.3 kadar bir artış sağladığını, yıllık yağışın 200-400 mm ve ortalama sıcaklığın $11{ }^{\circ} C^{\prime}$ den yüksek olduğu yörelerde baklagillerin ekim nöbetine girmesi durumunda etkinin daha yüksek olduğunu rapor etmişlerdir. Araştırıcılar, en uygun sonuçların 3-6 yıllık süreyle, $20-30 \mathrm{~kg}$ da-1 azot ve $300-600 \mathrm{~kg} \mathrm{da}^{-1}$ miktarında saman halindeki malç uygulamalarında elde edildiğini, bu sınırların alt ve üstündeki uygulamalar ile sap halindeki uygulamalarda beklenen yararın azaldığını belirtmişlerdir. Araştırıcıların tespit ettiği diğer önemli bir sonuç ise toprak işlemeyle bitkisel artıkların toprağa karıştırılması durumunda verim artışı \%4.5 olurken, malç olarak kullanılması durumunda verim artışının \%12.6 kadar olduğu şeklindedir.

\section{Hasat indeksi}

Malç miktarının hasat indeksi üzerindeki etkisi önemli olmuş ( $P<0.01), 0,300,600$ ve $900 \mathrm{~kg}$ da-1 malç uygulamalarında sırasıyla \%29.8, 33.5, 34.1 ve 34.4 hasat indeksleri elde edilmiştir (Çizelge 3 ve Şekil 3). 
Çizelge 3. Malç miktarlarına göre hasat indeksleri, malç miktarı, lineer ve kuadratik etkilere ilişkin $\mathrm{F}$ değerleri.

\begin{tabular}{cccc}
\hline Malç miktarı $\left(\mathrm{kg} \mathrm{da}^{-1}\right)$ & Hasat indeksi $(\%)$ & \multicolumn{2}{c}{ Varyans analiz sonuçları } \\
\hline 0 & $29,8 \mathrm{~b}$ & Varyasyon kaynağı & $\mathrm{F}$ değeri \\
\hline 300 & $33,5 \mathrm{a}$ & Malç miktarı & $21.72^{* *}$ \\
\hline 600 & $34,1 \mathrm{a}$ & Lineer etki & $50.27^{* *}$ \\
\hline 900 & $34,4 \mathrm{a}$ & Kuadratik etki & $12.96^{* *}$ \\
\hline
\end{tabular}

**işaretli F değerleri \% 1 düzeyinde önemlidir.

\section{Hasat indeksi}

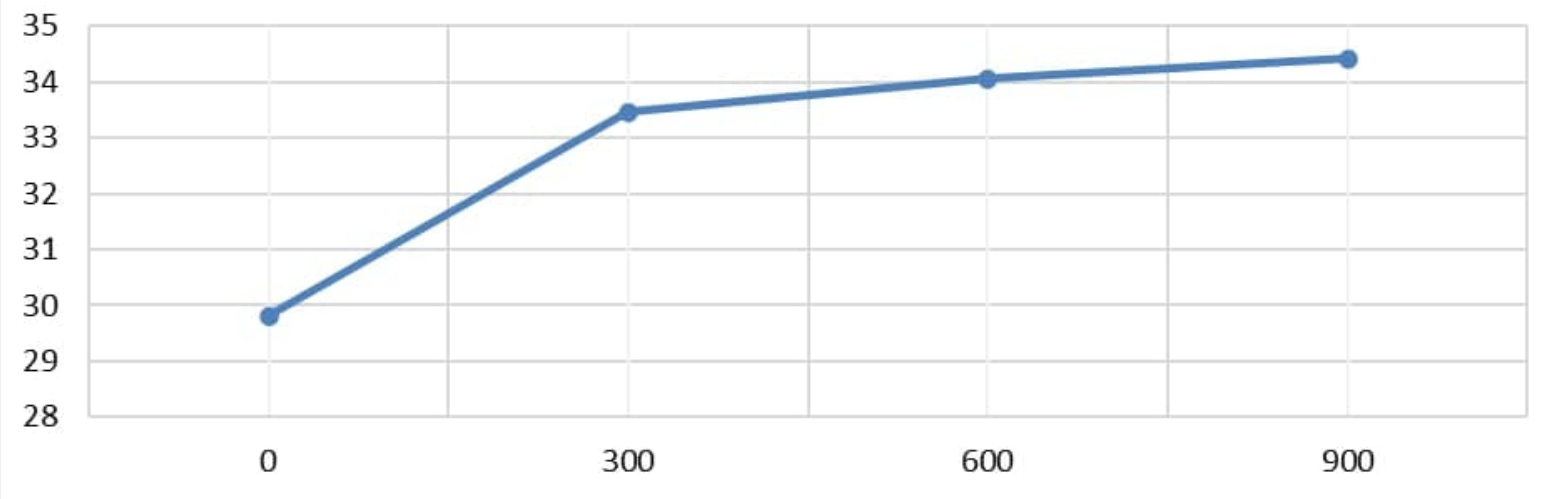

Şekil 3. Malç miktarlarına göre hasat indeksi.

Malç uygulamasının hasat indeksi üzerindeki lineer ve kuadratik etkilerinin her ikisi de önemli ( $P$ $<0.01$ ) bulunmuştur. Kontrole göre $300 \mathrm{~kg}$ malç uygulaması hasat indeksini önemli derecede artırmış, buna bağlı olarak lineer etki önemli bulunmuştur. Ancak 600 ve $900 \mathrm{~kg} \mathrm{da}^{-1}$ malç uygulamaları, $300 \mathrm{~kg} \mathrm{da}^{-1}{ }^{\prime} l i k$ malç uygulamasına göre hasat indeksinde önemli bir artış sağlamamış ve kuadratik etkinin önemli olduğu sonucuna varılmıştır.

$\mathrm{Bu}$ araştırmadan elde edilen sonuca benzer şekilde, Akter ve ark. (2018), tarla koşullarında 3 buğday çeşidinde (BARI Gom-26, BARI Gom-27 ve BARI Gom-28), hasat indeksi yönünden malç uygulamasının önemli etkiye sahip olduğunu tespit etmişlerdir. Jabran ve Aulakh (2015), buğday hasat indeksinin geleneksel toprak işlemede \%46.2 olurken, anıza ekimde arttığını ve \%49.8 olarak gerçekleştiğini bildirmişlerdir. Kahramanmaraş koşullarında 2017-2018 ürün yılında yapılan çalışmada, en yüksek hasat indeksi sapa kalkma dönemindeki $300 \mathrm{~kg}$ da-1 malç uygulamasında gerçekleşmiştir (Yılmaz, 2019).

\section{Sonuç ve Öneriler}

Kahramanmaraş koşullarında 2018-2019 ürün yılında yürütülen bu araştırmada $0,300,600$ ve 900 kg da-1 malç uygulamaları arasından en iyi sonuç dekara $300 \mathrm{~kg}$ malç uygulamasından elde edilmiştir. Malç miktarının biyomas üzerindeki kuadratik etkisi, tane verimi ve hasat indeksi üzerindeki lineer ve kuadratik etkileri önemli bulunmuştur. Bu araştırmadan elde edilmiş olan sonuçlara esas alınarak ekimler beraber 300 kg da-1 malç uygulaması önerilebilir. Ancak daha güvenilir önerilerde bulunmak için benzer nitelikte çalışmaların uzun yılları kapsayacak şekilde devam ettirilmesi yerinde olacaktır.

Teşekkür: Bu çalışma, KSÜ Araştırma Projeleri Yönetim Birimince desteklenen 2018/3-50A nolu projeye dayalı olarak hazırlanmıştır.

Çıkar Çatışması Beyanı: Makale yazarları aralarında herhangi bir çıkar çatışması olmadığını beyan ederler.

Araştırmacıların Katkı Oranı Beyan Özeti: Yazarlar makaleye eşit oranda katkı sağlamış olduklarını beyan ederler.

\section{Kaynaklar}

Akkaya, A. 1994. Buğday Yetiştiriciliği. Kahramanmaraş Sütçü İmam Üniversitesi Yayınları No: 1, Ziraat Fakültesi Yayınları No: 1, Kahramanmaraş.

Akter, S., Sarker, U.K., Hasan, A.K., Uddin, M.R., Hoque, M.M.I. ve Mahapatra, C.K., 2018. Effects of Mulching on Growth and Yield Components of Selected Varieties of Wheat 
(Triticum aestivum L.) under Field Condition. Archives of Agriculture and Environmental Science 3 (1), 25-35.

Anderson, R.L. 2005. Are some crops synergistic to following crop. Agronomy Journal, 97 (1); 710.

Baumhardt, R.L. ve Lascano, R.J., 1996. Rain infiltration as affected by wheat residue amount and distribution in ridged tillage. Soil Sci. Soc. Am. J. 60, 1908-1913.

Blanco-Canqui, H. ve Lal, R., 2007. Impacts of longterm wheat straw management on soil hydraulic properties under no-tillage. Soil Science Society of America Journal, 71: 11661173.

Chakraborty, D., Nagarajan, S., Aggarwal, P., Gupta, V.K., Tomar, R.K., Garg, R.N. Sahoo, R.N., Sarkar, A., Chopra, U.K., Sarma, K.S. ve Kalra, N., 2008. Effect of mulching on soil and plant water status, and the growth and yield of wheat (Triticum aestivum L.) in a semi-arid environment. Agricultural Water Management, 95 (12); 1323-1334.

Chakraborty, D., Garg, R.N., Tomar, R.K., Singh, R., Sharma, S.K., Singh, R.K., Trivedi, S.M., Mittal, R.B., Sharma, P.K. ve Kamble, K.H. 2010. Synthetic and organic mulching and nitrogen effect on winter wheat (Triticum aestivum L.) in a semi-arid environment. Agricultural Water Management, 97; 738748.

Chen, Y., Liu, T., Tian, X., Wang, X., Li, M., Wang, S. ve Wang, Z. 2015. Effects of plastic film combined with straw mulch on grain yield and water use efficiency of winter wheat in Loess Plateau. Field Crops Research, 172; 5358.

Chen, W., Zhangc, J. ve Dengb, X. 2019. The spike weight contribution of the photosynthetic area above the upper internode in a winter wheat under different nitrogen and mulching regimes. The Crop Journal, 7 (1); 89-100.

Ebrahimian, E., Koocheki, A., Mahallati, M.N., Khorramdel, S. ve Beheshti, A. 2016. The effect of tillage and wheat residue management on nitrogen uptake efficiency and nitrogen harvest index in wheat. Turkish Journal of Field Crops, 21 (2); 233-239.

Erenstein, O. 2002. Crop residue mulching in tropical and semi-tropical countries: An evaluation of residue availability and other technological implications. Soil \& Tillage Research, 67; 115-133.

Gerek, R. 1968. Dryfarming İstasyonu tarafından yapılmış olan nadas hazırlığı ve toprak verimliliği denemeleri. Eskişehir Tohum Islah ve Deneme İst. 6, Eskişehir.

Huang, Y., Chen, L., Fu, B., Huang, Z. ve Gong, J., 2005. The wheat yields and water-use efficiency in the Loess Plateau: straw mulch and irrigation effects. Agricultural Water Management, 72; 209-222.

Huang, G., Chai, Q., Feng, F. ve Yu, A. 2012. Effects of different tillage systems on soil properties, root growth, grain yield, and water use efficiency of winter wheat (Triticum aestivum L.) in Arid Northwest China. Journal of Integrative Agriculture, 11 (8); 1286-1296.

Jabran, K. ve Aulakh. A. 2015. Higher Yield and Economic Benefits for Wheat Planted in Conservation Till Systems. Yüzüncü Yıl Üniversitesi Tarım Bilimleri Dergisi, 25 (1): 78-83.

Kahlon, M.S., Lal, R. ve Ann-Varughese, M. 2013. Twenty two years of tillage and mulching impacts on soil physical characteristics and carbon sequestration in Central Ohio. Soil and Tillage Research, 26; 151-158.

Lentz, R.D. ve Bjorneberg, D.L., 2003. Polyacrylamide and straw residue effects on irrigation furrow erosion and infiltration. Journal of Soil and Water Conservation, 58; 312-319.

Malhi, S.S. ve Kutcher, H.R. 2007. Small grains stubble burning and tillage effects on soil organic $\mathrm{C}$ and $\mathrm{N}$, and aggregation in northeastern Saskatchewan. Soil \& Tillage Research, 94; 353-361.

Malhi, S.S.ve Lemke, R. 2007. Tillage, crop residue and $\mathrm{N}$ fertilizer effects on crop yield, nutrient uptake, soil quality and nitrous oxide gas emissions in a second 4-yr rotation cycle. Soil \& Tillage Research, 96; 269-283.

Montenegro, A.A.A., Abrantes, J.R.C.B., de Lima, J.L.M.P., Singh, V.P. ve Santos, T.E.M. 2013. Impact of mulching on soil and water dynamics under intermittent simulated rainfall. Catena, 109; 139-149.

Qi, G., Kang, Y., Yin, M., Ma, Y., Bai, Y. ve Wang, J. 2019. Yield Responses of Wheat to Crop Residue Returning in China: A Meta-Analysis. Crop Science, 59: 2185-2200.

Rahman, M.A., Chikushi, J., Safizzaman, M. ve Lauren, J.G. 2005. Rice straw mulching and nitrogen response of no-till wheat following rice in Bangladesh. Field Crops Research, 91; 71-81.

Ram, H., Dadhwal, V., Vashist, K.K., Kau, H., 2013. Grain yield and water use efficiency of wheat (Triticum aestivum L.) in relation to irrigation levels and rice straw mulching in North West 
India. Agricultural Water Management, 128; 92-101.

SAS. 1999. Statistical Analysis System User' Guide Statistics. SAS Institute Inc. Cary NC 27513 USA.

Shah, S.S.H., Ul-Hassan, A., Ghafoor, A. ve Bakhsh, A. 2013. Soil physical characteristics and yield of wheat and maize as affected by mulching materials and sowing methods. Soil Environment, 32 (1); 14-21, 2013.

Sidhu, H.S., Singh, M., Humphreys, E., Singh, B., Dhillon, S.S., Blackwell, J., Bector, V., Malkeet, S. ve Sarbjeet, S. 2007. The Happy Seeder enables direct drilling of wheat into rice stubble. Australian Journal of Experimental Agriculture, 47; 844-854.

Singh, B., Humphreys, E., Eberbach, P.L., Katupitiya, A., Singh, Y. ve Kukal, S.S. 2011. Growth, yield and water productivity of zero till wheat as affected by rice straw mulch and irrigation schedule. Field Crops Research, 121; 209225.

Singh, Y., Singh, B. ve Timsina, J. 2005. Crop residue management for nutrient cycling and improving soil productivity in rice-based cropping systems in the tropics. Advances in Agronomy, 85; 269-407.

Stagnari, F., Galieni, A., Speca, S., Cafiero, G. ve Pisante, M. 2014. Effects of straw mulch on growth and yield of durum wheat during transition to Conservation Agriculture in
Mediterranean environment. Field Crops Research, 167, 51-63.

Tolk, J.A., Howell, T.A. ve Evett, S.R. 1999. Effect of mulch, irrigation, and soil type on water use and yield of maize. Soil and Tillage Research, 50 (2); 137-147.

Turmel, M.S., Speratti, A., Baudron, F., Verhulst, N., Govaerts, B., 2015. Crop residue management and soil health: A systems analysis. Agricultural Systems, 134; 6-16.

Yılmaz, M.A. 2019. Kahramanmaraş Koşullarında Bitkisel Malç Uygulama Miktar ve Zamanının Ekmeklik Buğdayda Verim, Verim Unsurları ve Fotosentez Özelliklerine Etkileri. (Yüksek lisans tezi) Erişim adresi: https://tez.yok.gov.tr/UlusalTezMerkezi

Zhang, G.S., Chan, K.Y., Li, G.D. ve Huang, G.B. 2008. Effect of straw and plastic film management under contrasting tillage practices on the physical properties of an erodible loess soil. Soil \& Tillage Research, 98; 113-119.

Zhang, S., Lövdahl, L., Grip, H., Tong, Y., Yang, X. ve Wang, Q. 2009. Effects of mulching and catch cropping on soil temperature, soil moisture and wheat yield on the Loess Plateau of China. Soil \& Tillage Research, 102; 78-86.

Zribi, W., Aragués, R., Medina, E. ve Faci, J.M. 2015. Efficiency of inorganic and organic mulching materials for soil evaporation control. Soil and Tillage Research, 148; 40-45. 